\title{
Application of digital technologies for sustainable product management in a circular economy: A review
}



Christian Doppler Laboratory for Sustainable Product Management enabling a Circular Economy; Institute of Systems Sciences, Innovation and Sustainability Research, University of Graz, Graz, Austria

\section{Correspondence}

Magdalena Rusch, Christian Doppler

Laboratory for Sustainable Product

Management enabling a Circular Economy;

Institute of Systems Sciences, Innovation and

Sustainability Research, University of Graz,

Merangasse 18/II, $8010 \mathrm{Graz}$, Austria.

Email: magdalena.rusch@uni-graz.at

\section{Funding information}

Christian Doppler Research Association; National Foundation for Research, Technology and Development; Austrian Federal Ministry for Digital and Economic Affairs; University of Graz

\begin{abstract}
Digital technologies (DTs), such as the Internet of Things, big data, artificial intelligence, or blockchain, are considered as enablers for a more sustainable and circular economy. So far, literature on these topics has mostly focused on specific DTs and subareas of sustainable product management (SPM). The aim of this paper is to provide a more comprehensive overview of current and potential examples of DT applications in SPM (e.g., product design/assessment, supply chain management, and business models). The collected examples $(n=146)$ were analyzed based on a systematic literature review, using quantitative and qualitative content analysis. Deductive and inductive analyses of the examples revealed the potential of DTs in terms of their usability along the product life cycle, their role as enablers for circular economy strategies and in specific SPM activities. DT application often entails only incremental improvements, for example, increased efficiency of existing processes, with more radical forms of improvement remaining relatively scarce. There is clear room for greater adoption and optimization of DTs, in various areas of SPM, so as to accelerate the transition towards a more sustainable and circular economy.
\end{abstract}

\section{KEYWORDS}

circular economy, digitalization, eco design, LCA, sustainability, sustainable product development

\section{1 | INTRODUCTION}

Information and knowledge have become indispensable resources in supporting modern social progress and economic development (Weckenmann et al., 2019). Industry 4.0, as a blend of new digital

Abbreviations: Al, artificial intelligence; $\mathrm{BOL}$, beginning-of-life; $\mathrm{CBMs}$, circular business models; CE, circular economy; DTs, digital technologies; EC, European Commission; EMF, Ellen MacArthur Foundation; EOL, end-of-life; Freq., frequency; loT, Internet of Things; LCA, life cycle assessment; LCI, life cycle inventory; MOL, middle-of-life; PLCD, product life cycle data; PSS, product-service systems; ReSOLVE, regenerate, share, optimize, loop, virtualize, and exchange; RQs, research questions; SCM, supply chain management; SPM, sustainable product management; SSCM, sustainable supply chain management; UNEP, United Nations Environment Programme; WBCSD, World Business Council for Sustainable Development. technologies (DTs), may be perceived as a facilitator in the current knowledge-based society (Manavalan \& Jayakrishna, 2019; Weckenmann et al., 2019). Advanced and potentially disruptive applications from Industry 4.0 (Kouhizadeh et al., 2020) are, for example, the emergence of the Internet of Things (IoT), artificial intelligence (Al), big data analytics, or blockchain technology-collectively known as DTs (European Commission [EC], 2020; Kristoffersen et al., 2019). They play an increasingly vital role in the transition towards a more sustainable and circular economy (CE) (Pagoropoulos et al., 2017), for example, by enabling innovative ways of monitoring and optimizing product performances (Rosa et al., 2020) and improving the quality of product management over time (Rocca et al., 2020). In the EU's CE

This is an open access article under the terms of the Creative Commons Attribution-NonCommercial-NoDerivs License, which permits use and distribution in any medium, provided the original work is properly cited, the use is non-commercial and no modifications or adaptations are made.

(c) 2022 The Authors. Business Strategy and The Environment published by ERP Environment and John Wiley \& Sons Ltd. 
action plan it is stated that the use of those four DTs (IoT, Al, big data, and blockchain) will contribute to "[...] a closer relationship with customers, mass customisation, the sharing and collaborative economy" (p. 2) which can then contribute to an acceleration of product and resource circularity and the dematerialization of the economy (EC, 2020). The CE and Industry 4.0 requirements are pushing companies to invest in DTs in order to make information available throughout product life cycles (Awan et al., 2021). For example, information about the original design specifications of a product can be used to facilitate different R-strategies ${ }^{1}$ like reuse, repair, or recycling (Yang et al., 2018). However, acquiring the requisite data is often difficult (Kouhizadeh et al., 2020; Rocca et al., 2020). So far, most companies have not yet developed the necessary "digital maturity," and the requisite information flows have not yet been well defined or established (Ingemarsdotter et al., 2020; Kurilova-Palisaitiene et al., 2015). Nevertheless, research shows that DTs do enable circular business models (CBMs) that foster various R-strategies and allow for a greater strategic fit between customers, coproviders, and stakeholders (Bressanelli et al., 2018; Ranta et al., 2021) and they are used to facilitate the implementation of product-service systems (PSS) (Ingemarsdotter et al., 2020). Although, at the product level, research on Industry 4.0 and on sustainability may be viewed as two independent fields, interest in the intersection of the two fields is growing (Beltrami et al., 2021; Rosa et al., 2020). In particular, the number of studies on the intersection of Industry 4.0, DTs, and CE has recently grown considerably (Cagno et al., 2021; Massaro et al., 2021; Pagoropoulos et al., 2017). However, while several of these studies describe the potential of specific DTs in certain CE strategies (e.g., Ingemarsdotter et al., 2020; Lopes de Sousa Jabbour et al., 2018) or describe initial cases of successful implementation (e.g., Nobre \& Tavares, 2017), a comprehensive and comparative review of DTs in sustainable product management (SPM) is still lacking. Moreover, the studies that focus on the CE in general (e.g., Bressanelli et al., 2018), or on specific aspects of it (e.g. Garrido-Hidalgo et al., 2020), often do not adopt a sufficiently broad perspective, and in particular, tend to neglect the social dimension of sustainability.

This study sets out to provide a comprehensive overview of where and how different DTs can support companies in their circular and SPM efforts. Applying this wider SPM lens allows for new insights regarding DT potential in moving towards a CE and improving sustainable product design, sustainability assessment (including the social dimension), or sustainable supply chain management (SSCM). Thus, this study addresses the following two research questions (RQs):

RQ 1: What potential or existing applications of DTs for SPM are described in the literature?

RQ 2: How could the utilization of DTs facilitate SPM in a CE?

\footnotetext{
${ }^{1}$ This study follows the value-retention options (also called R-hierarchy, R-imperatives, or simply R's) established by Reike et al. (2018): R0 refuse, R1 reduce, R2 reuse/resell, R3 repair $\mathrm{R} 4$ refurbish, $\mathrm{R} 5$ remanufacture, $\mathrm{R} 6$ repurpose, $\mathrm{R} 7$ recycle materials, $\mathrm{R} 8$ recover energy, and R9 re-mine.
}

The study's main contribution concerns the review and categorization of DT applications that have already been identified as useful in SPM. First, the extent to which DTs may support the implementation of different CE strategies is described. Second, the product life cycle phases in which DTs exhibit their greatest potential are shown, as is how they can support product life cycle management. More specifically, the analysis reveals how DTs can benefit different areas and specific activities of SPM at the operational level of a firm. Throughout, a distinction is made between conceptual and existing cases, that is, between "potentials" and "applications." This serves to provide an estimate of DT implementation. The study is thus intended to help pinpoint how DTs may be used in future, to help make products more circular and more sustainable.

The remainder of this paper is structured in the following way: Section 2 provides the theoretical background on CE, SPM, and a brief introduction concerning the included DTs. The methods used are described in Section 3. The results from the quantitative and qualitative content analysis are presented in Section 4. This is done by showing the collected and categorized DT examples. The results are discussed in Section 5. Finally, in Section 6, conclusions and managerial implications are derived, and the study's limitations are presented.

\section{2 | THEORETICAL BACKGROUND}

This section introduces the concepts and DTs used in this study. First, an outline of the CE concept and the six corresponding CE strategies from the ReSOLVE framework is given. The conceptual focus then shifts to a broader sustainability perspective, which is the paper's main focus. Finally, definitions of the four DTs used in this study (AI, big data, loT, and blockchain) are provided.

\subsection{Circular economy and the ReSOLVE framework}

In today's linear economy, the lack of a comprehensive and integrated view of products' physical life cycles leads to products being designed and used in an unsustainable way (Geissdoerfer et al., 2017; Mayer et al., 2018). One alternative to the linear economy now gaining momentum in business, politics, and academia is the concept of a CE (EC, 2020; Ellen MacArthur Foundation [EMF], 2015; Schöggl et al., 2020). In a CE, material flows are supposed to preserve their highest value as long as possible and to circulate in loops within the economy in order to minimize waste and negative environmental impacts (Kirchherr et al., 2017).

The ReSOLVE framework (EMF, 2015) can help operationalize the concept of a CE by categorizing the different business opportunities needed in the generation of circularity strategies. This framework, used in one of the analyses in this paper, includes the following circularity strategies: regenerate, share, optimize, loop, virtualize, and exchange (see Appendix B in the Supporting Information for a description of each ReSOLVE strategy). Previous literature, for example, 
Lopes de Sousa Jabbour et al. (2018), examines how applications from Industry 4.0 interplay with the ReSOLVE framework and sustainable operations management. Kouhizadeh et al. (2020) use the ReSOLVE framework to explore how specific (critical) technologies in an Industry 4.0, such as blockchain technology, could transform and advance the realization of a CE. However, current barriers impeding the operationalization of a CE include, for example, the lack of information concerning a product's life cycle, or the lack of technological know-how with respect to product design or integration in product development (Chauhan et al., 2021; de Jesus \& Mendonça, 2018; Kirchherr et al., 2018).

\section{2 | Sustainable product management}

While the concept of a CE has witnessed a considerable boom in both theory and practice in recent years, it should not be considered as a new sustainability paradigm (Geissdoerfer et al., 2017), but rather as one of several complementary strategies for achieving sustainability (Geissdoerfer et al., 2017; Schöggl et al., 2020). This has become evident in a growing number of publications that show that both $\mathrm{CE}$ research (Korhonen et al., 2018; Murray et al., 2017; Schögg| et al., 2020) and CE practice (Stumpf et al., 2021) tend to fall short when it comes to establishing a comprehensive approach towards sustainability. However, as it is the specific intention of the present paper to focus on a comprehensive approach, we adopt the term SPM. This is used throughout the text. Unlike CE, SPM is not an established concept. Instead, it represents an umbrella term for several established concepts underpinning comprehensive sustainabilityoriented management at the product level. Examples of such established concepts/practices, besides CE, are SSCM (Seuring \& Müller, 2008), eco design (Brezet \& van Hemel, 1997), design for sustainability (Ceschin \& Gaziulusoy, 2016; Spangenberg et al., 2010), and sustainability assessment (e.g., life cycle assessment [LCA], ISO, 2006; or social LCA, United Nations Environment Programme [UNEP], 2020).

For organizations, the goal of SPM is to investigate under which conditions their products or services are designed, produced, and used to maximize sustainability performance and its circularity. In this regard, making informed decisions means that product sustainability and circularity performance need to be assessed on a case-specific level. Such endeavors tend to be highly context dependent and their management is often counterintuitive (Främling et al., 2013). Tracking each step of a supply chain and carrying out sustainability assessments entail considerable time, data and effort (Belaud et al., 2019). Also, using sustainability assessment results for developing sustainable products is not always a straightforward task and can be seen as a "multi-criteria decision problem" which inter alia needs increased transparency of design solutions to allow for better-informed decision making (Buchert et al., 2019). SPM practices share a comprehensive life cycle perspective and involve an inherent dependency on exchanging material and product-related information (Främling et al., 2013; Vadoudi et al., 2014). A life cycle perspective relates to the different phases of a physical product life, and they can be summarized under three main stages: beginning-of-life (BOL), middle-oflife (MOL), and end-of-life (EOL) (Terzi et al., 2010).

The product and material information flows at the $\mathrm{BOL}$ stage are quite complete as various information systems such as computeraided design, or product data management are already in place (Vadoudi et al., 2014). After the BOL phase, the product and materialrelated information become vaguer and insufficiently managed (Vadoudi et al., 2014). A closed-loop and comprehensive flow of product and material information is imperative for implementing SPM. Thus, companies need to manage every single stage in which products are handled and distributed (Garrido-Hidalgo et al., 2019). However, the need to manage downstream product flows (manufacturer to the customer) and upstream flows (customer to manufacturer) with multiple value-retention options is generating an increasing number of uncertainties for organizations (Garrido-Hidalgo et al., 2019; Jerbia et al., 2018).

\section{3 | Digital technologies}

DTs have already encouraged a paradigm shift in industrial production (Kristoffersen et al., 2019). In general, the availability of technical solutions can be considered as a facilitator in the economy's dematerialization (EC, 2020). The development towards a CE is thus also reliant on a wide array of technologies (de Jesus \& Mendonça, 2018; Pagoropoulos et al., 2017). According to the EU's CE action plan (EC, 2020) and the European Circular Economy Research Alliance (Berg et al., 2020), the use of loT, big data, Al, and blockchain offers great potential for increasing the sustainability and circularity of products and resources. We thus focus on these four technologies in the present study.

1. The loT provides new communication capabilities, increasing device interconnectedness, and leads to the formation of new information networks (Garrido-Hidalgo et al., 2019). loT is one of the most crucial Industry 4.0 applications improving CE performance parameters and helping to achieve CBMs (Chauhan et al., 2021). As identified by Atzori et al. (2010), the loT can be realized in three paradigms: internet oriented (middleware), things oriented (sensors), and semantic oriented (knowledge), and their alignment is central to the usefulness of the loT (Gubbi et al., 2013).

2. Al generally refers to technologies that are capable of performing certain tasks as well as, or better than, humans (Vinuesa et al., 2020), such as machine learning and deep learning (Copeland, 2016).

3. Big data analytics refers to the strategy of analyzing large quantities of data that can be distinguished by their volume, variety, velocity, veracity, variability, and value (Sivarajah et al., 2017).

4. The most recent DT is blockchain technology, a distributed ledger database that records transaction data and other information. It is characterized as a chain of time-stamped and cryptographically 
secured digital information that facilitates reliable, decentralized data sharing (S. Li et al., 2020).

\section{3 | METHODS}

The present exploratory research study combines a keyword-based systematic literature review (Okoli \& Schabram, 2010) with quantitative and qualitative content analyses of selected papers. The main elements and processes are described in Figure 1, and more detailed material (including the keyword string) can be found in Table A1. A keyword search process in literature databases is particularly suitable for covering a specific topic addressed across a variety of academic fields or journals (Seuring \& Gold, 2012). First, the resulting literature sample was analyzed quantitatively, and second, qualitative content analysis was then used for a subset of the sample. Qualitative content analysis is an effective means of conducting literature reviews transparently and systematically (Fink, 2005; Seuring \& Gold, 2012). It is based on the approach described by Mayring (2014). Mayring (2014) describes three forms of interpretation, one of which, "structuring," was applied in the present study to filter out particular aspects of the papers' content (p. 64).

\section{1 | Paper selection}

Using the Scopus database, two rounds of data collection were undertaken for the literature review. Three hundred seventy-five articles were found in the search process from March 1-4, 2019. This sample was used for the qualitative analysis of the papers. In a later search, on July 29, 2020, using the same search queries, 619 articles (including duplicates due to overlaps between the categories) were found (see Tables A2 and A3). New papers were added to the sample from 2019, and the overall distribution of published papers could be compared. Sustainability terms (i.e., CE, product lifecycle management, LCA, life cycle analysis, eco design, [green/sustainable] supply chain management [SCM], industrial ecology, and life cycle management) and DT terms (i.e., loT, big data, blockchain, artificial intelligence, and Industry 4.0) were used to identify the articles. Figure 1 shows the selection process and the number of documents found in each research step.

The first step entailed identifying those articles containing the designated keywords (at least one sustainability term and one DT term) in the article's title, keywords, or abstract. After removing the duplicates, 233 out of 375 articles remained for further investigation. Automatic coding via the function "extended lexical search" in MAXQDA was applied using the same keywords to screen the full text of the articles. Documents, where none of the DTs were stated explicitly in the main text of the article, were excluded from the sample $(n=33)$. Second, the automated coding function (based on the extended lexical search) and an abstract screening process were used to eliminate articles which did not focus explicitly on DTs (i.e., those which used DT terms less than five times) $(n=46)$. The March 2019 procedure was repeated in July 2020 in order to include more recent publications in the field. In total, 186 articles (154 articles from March 2019 and an additional 32 articles from July 2020) were used for the qualitative content analysis.

\section{2 | Paper analysis}

The quantitative analysis was performed using the "R" statistical program version 4.0.2 (R Core Team, 2019) and Excel sheets. For the qualitative content analysis, conducted in MAXQDA, a combination of deductive and inductive coding was used (see Figure B1 in the Supporting Information). First, the 186 documents were read and analyzed to collect potential (conceptual) or application (already implemented or case study) examples of DTs used for SPM. This step resulted in a collection of 146 examples that were further categorized in terms of the DT mainly employed (i.e., big data analytics, loT, blockchain technology, and $\mathrm{Al}$ ) and the life cycle stages addressed

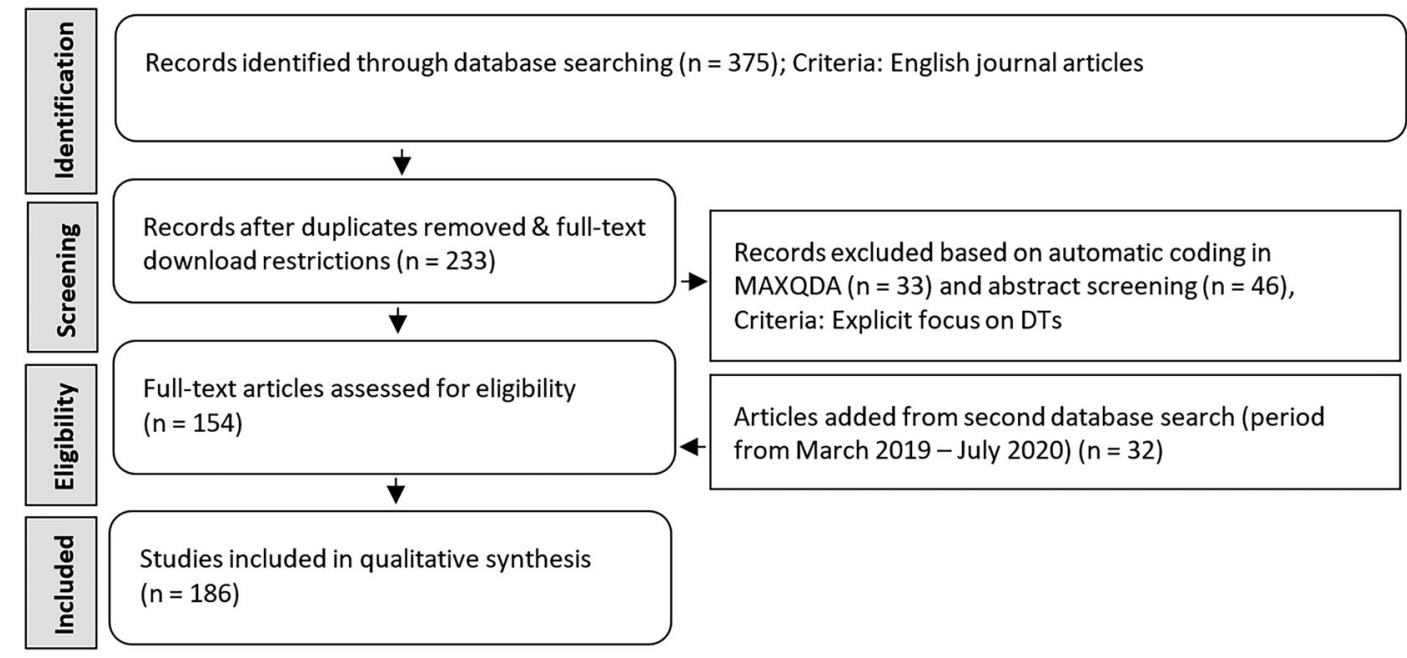

FIGURE 1 Flow of information through the different phases of a systematic review (own representation based on Moher et al., 2009, p. 3) 


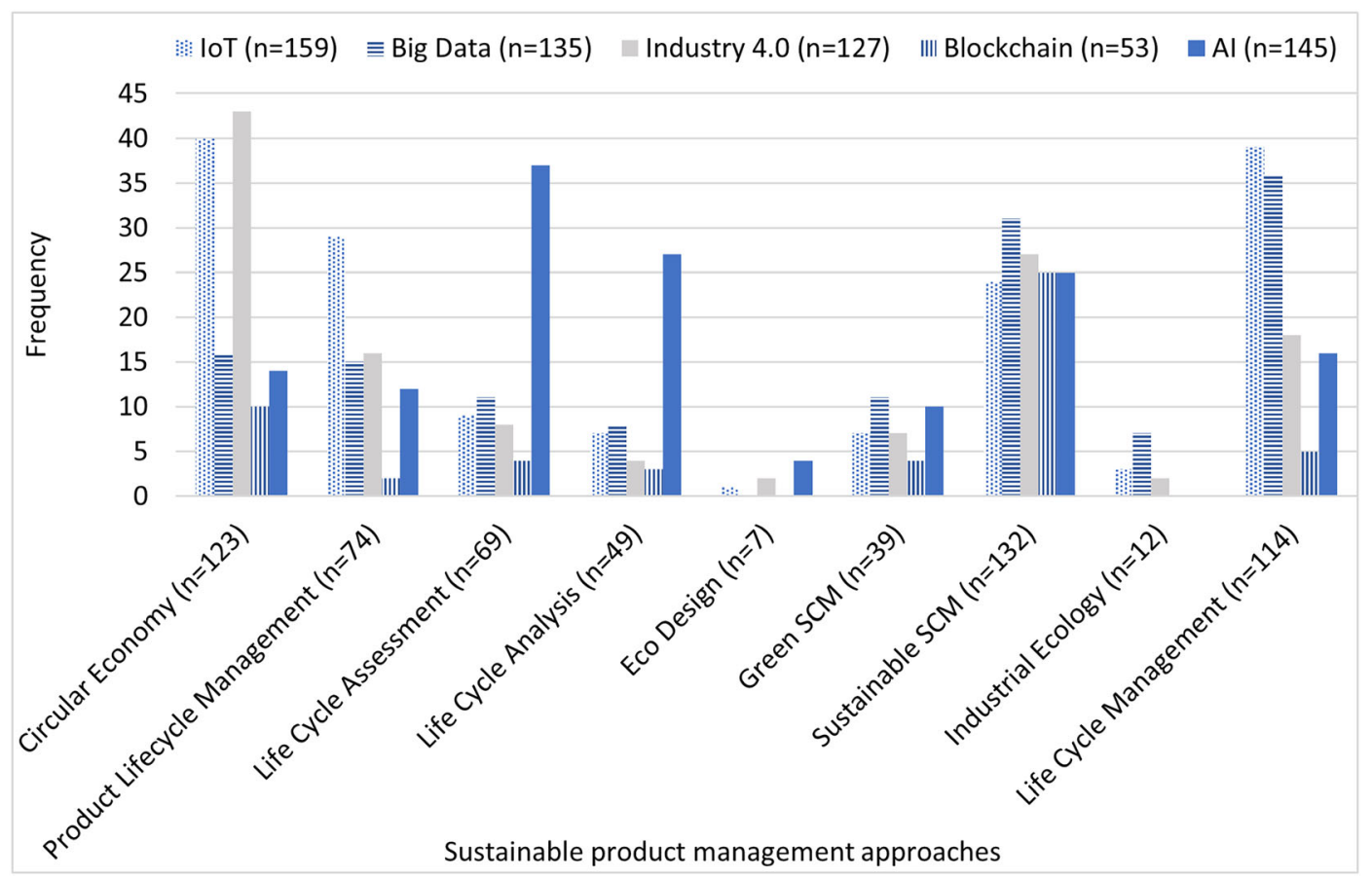

FIGURE 2 Categorization of documents per sustainability and digital technology terms $(n=619)$. Abbreviations: loT, Internet of Things; Al, artificial intelligence; SCM, supply chain management

(BOL, MOL, and EOL-multiple selection possible). Furthermore, the DT examples were categorized by using the ReSOLVE framework. The ReSOLVE framework was chosen, first, because of its concise, yet differentiated collection of CE strategies. Second, as outlined in Section 2.1, the framework was also the most frequently used classification scheme in previous conceptual studies on the role of DTs for CE. This enables comparisons between the findings. The allocation of the examples to one of the six CE strategies (regenerate, share, optimize, loop, virtualize, and exchange) was done based on best fit to example descriptions. Finally, an inductive coding approach was used to identify and categorize which SPM areas, outcomes, or aspects can benefit from the application of DTs.

\subsection{Quality criteria}

Adequate transparency and documentation of the research steps was ensured by providing the keywords and search strings that were used for the Scopus data collection (Appendix A). The deductive and inductive coding approaches were disclosed and illustrated (Appendix B in the Supporting Information), and a thorough review protocol, including the 146 identified examples, was compiled. Additionally, other researchers reviewed the search terms and database. Two independent coders allocated the examples to the ReSOLVE strategies (Section 4.2). The ex post agreement between the two coders was measured using Cohen's kappa (Lombard, 2002) and was found to be 0.89 , which according to Landis and Koch's (1977) classification scheme represents an "almost perfect" overlap. The allocation to the remaining categories was done in three joint discussion rounds (see Sections 4.3-4.5). For these rounds, initial coding by one of the present authors served as input; then, the two other coders reviewed the coding process, and the results were discussed. This approach was used for the inductive coding approach and categorization of the DT examples.

\section{4 | RESULTS}

The results section progresses from general to specific insights. First, the literature development of the field is illustrated in Section 4.1. Then, the role of DTs as enablers in the six general ReSOLVE strategies (Section 4.2) and their usability in three different product life cycle phases are described (Section 4.3). Finally, using the wider lens of SPM (as described in Section 2.2), the specific benefits of DTs in different areas are discussed (Section 4.5).

\subsection{Development of the literature}

The overall distribution and number of documents found by combining each sustainability and each DT term can be seen in Figure 2. In terms of the prevalence of the different DTs in the 619 papers, loT was the search term that was referred to the most (159 documents), followed by $\mathrm{Al}^{2}$ (145 documents) and big data (135 documents). In the

${ }^{2}$ While Al was the second most frequently used keyword, the detailed qualitative analyses (presented in Sections 4.2-4.5) revealed that frequent occurrence of this keyword does not reflect the prevalence of Al-related research. Apparently, the keyword Al was frequently assigned wrongly to papers that do not even mention Al technology but only use references that have the word "Artificial Intelligence" in the title. 
sustainability field, most articles were found for SSCM (132 documents), CE (123 documents), and life cycle management (114 documents). The highest bars in Figure 2 show the most prevalent combination of search terms. CE was often combined with Industry 4.0 (43 documents) and also with loT (40 documents). The keyword combination LCA with Al resulted in 37 documents. In the SSCM field, all DT terms were used almost equally often. The combination of the keywords life cycle management and loT resulted in 39 documents. Life cycle management combined with big data resulted in 36 documents

A very high increase of articles was observed using the terms blockchain and Industry 4.0 (Figure 3) as well as CE and SSCM (Figure 4). For example, from March 2019 to July 2020, the number of articles related to blockchain technology increased from 7 to 53 articles, and by using the term Industry 4.0, the results increased from 52 to 127 articles.

In addition, a popular keyword used in the literature is CE. For this, there was an increase from 45 to 123 studies. Also, the number of articles found using the search term SSCM increased significantly from 55 to 132 (Figure 4).

For the qualitative content analysis, the documents from the literature search processes were condensed to a sample of 186 articles (154 articles from March 2019 and an additional 32 articles from July 2020) by eliminating duplicates ${ }^{3}$ between the categories and selecting articles with a focus on DT applications for SPM practices (see Figure 1). The descriptions of the examples varied in their level of detail, ranging from rather superficial descriptions (e.g., loT-based dynamic carbon footprint approach) to very detail-rich descriptions of concrete DT applications in SPM practice. From a total of 146 examples, 66 examples were identified where DTs were already being used by an organization or where a case study was being conducted (here, and in the following, these are referred to as "applications"). The other 80 examples are only conceptual descriptions of how DTs could be used for SPM (referred to as "potentials").

\section{2 | Digital technologies and circular economy strategies}

In order to detail DTs' role in the realization of CE strategies, the examples examined were allocated to one of the six strategies of the ReSOLVE framework. From the 146 examples, 102 (i.e., more than $2 / 3$ of all examples) contributed to the CE strategy "optimize," 21 examples were allocated to the strategy "loop," 13 examples to "virtualize," 6 examples to "share," and 4 to "regenerate." None of the DT examples in the present study was found to contribute to the strategy "exchange" (Figure 5).

Selected loT examples (Figure 5a) that contribute to the strategy "optimize" (freq. $=22$ ) are sensors that can collect real-time data to

${ }^{3}$ Overlaps were not eliminated in this first research step because the intention was to get an overview of which DT is most often associated with which SPM approach. Eliminating the overlapping documents earlier would have made such an overview impossible.

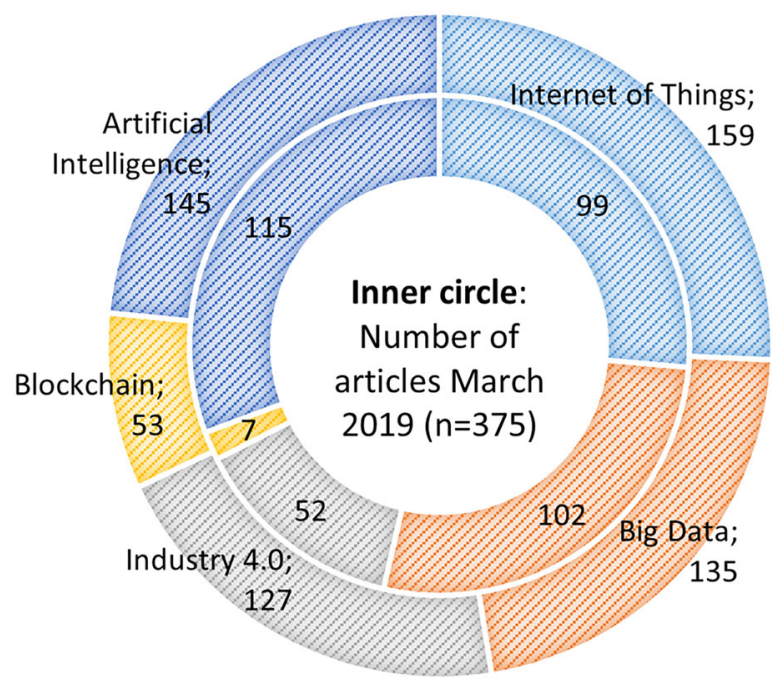

Outer circle: Number of articles July $2020(n=619)$

FIGURE 3 Aggregated Scopus search results for digital technology terms. The inner circle shows the number of articles found on March 1-4, 2019, and the outer circle the results from July 29,2020

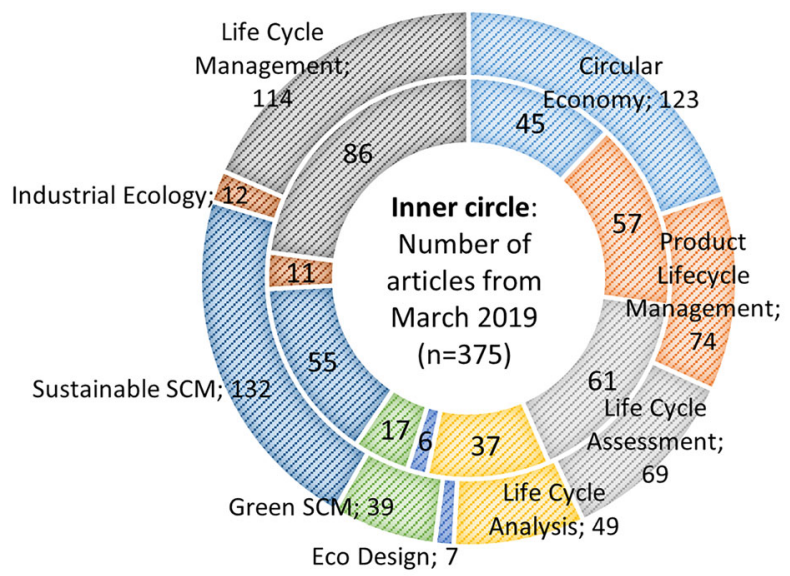

Outer circle: Number of articles from July $2020(n=619)$

FIG URE 4 Aggregated Scopus search results for sustainability terms. The inner circle shows the number of articles found on March 1-4, 2019, and the outer circle the results from July 29, 2020. Abbreviation: SCM, supply chain management

detect anomalies in production processes and equipment as indications of potential failures. A notification message is then sent to the user to prevent critical damage (Kim et al., 2017). An loT-based dynamic carbon footprint approach is suggested in the literature to reduce uncertainties in carbon footprint assessment (Tu et al., 2017). Big data analytics can enhance the supply chain traceability performance which can reduce thousands of hours of accessing, integrating, and managing product databases that capture products for recall or retrofitting (Kaleel Ahmed et al., 2018). For Al, the least examples 
FIGURE 5 Classification of

(a) potential $(n=80)$ and

(b) application $(n=66)$ examples of digital technologies allocated to the circular economy ReSOLVE framework. Total $n=146$.

Abbreviations: Freq., frequency; Re, regenerate; $\mathrm{S}$, share; $\mathrm{O}$, optimize; $\mathrm{L}$, loop; V, virtualize; E, exchange; DTs, digital technologies (a) Potentials

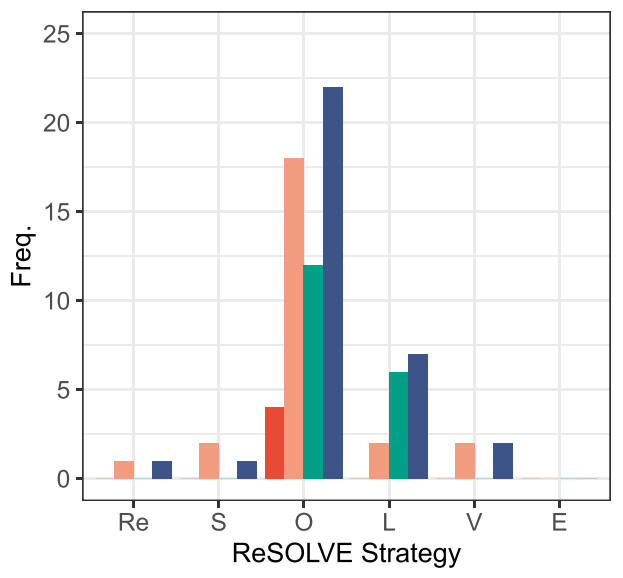

(b) Applications

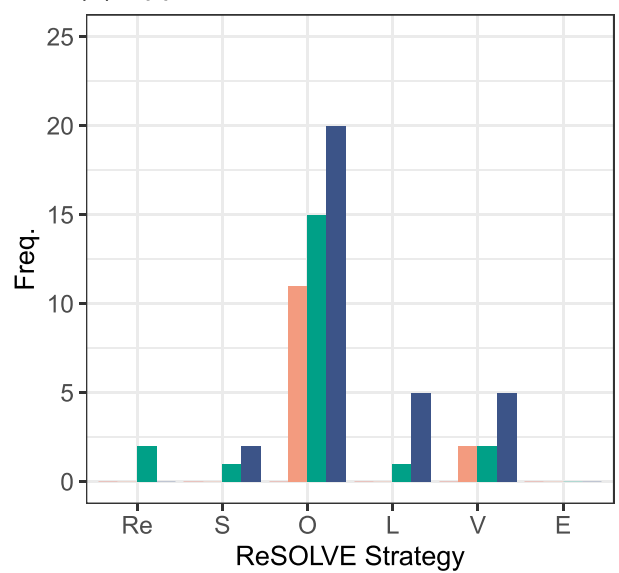

DT Artificial Intelligence

Big Data

Blockchain

Internet of Things

were found. This was also confirmed in another recent review (Awan et al., 2021).

Additionally, there are concrete examples of loT applications (Figure 5b) (freq. = 20). For instance, Rolls-Royce monitors its products' engine data for the purpose of extending the life of engines in use (Bressanelli et al., 2018). Cisco Energy Management applies loT technology to measure the energy use of products and displays it to the user so that actions can be taken to improve operational efficiency (Ingemarsdotter et al., 2019).

Blockchain technology is often (freq. $=15$ ) used to optimize business operations. For example, Ikea uses blockchain technology to increase supply chain transparency to ensure that purportedly green products are in fact environmentally friendly (Saberi et al., 2019). In the automotive sector, General Motors and BMW adopt and apply blockchain technology to share self-driving car data across interorganizational and intraorganizational platforms (Kouhizadeh et al., 2020).

\section{3 | Digital technologies along a product life cycle}

The potential and applied DT examples were classified based on their point of contribution along a product life cycle (BOL, MOL, EOL, or multiple selections) (Figure 6).

In the current literature, potential examples of how DTs could contribute to SPM were often described for the BOL phase using big data analytics or loT (Figure 6a). For the BOL stage, big data analytics (freq. $=12$ ) was used to create comprehensive supplier profiles in order to choose qualified suppliers (Kaleel Ahmed et al., 2018). Also, a large volume of data can be compared effectively when optimizing the development of a new product (e.g., in the conceptual design stage) (J. Li et al., 2015). The BOL phase is crucial because original equipment manufacturers (OEMs) and suppliers can predefine reuse or recycle features in the early product development phases (Ge \& Jackson, 2014). Incorporating loT applications into the product (design) was also mentioned in the literature (freq. $=6$ ). For example, chips or sensors can collect and contain data to inform users of the product's components and materials. Also, information on how the product can be disassembled and recycled at the end of its useful life, for example, in the form of a product passport, can also be included (Lopes de Sousa Jabbour et al., 2018).

For the MOL stage, the use of loT technology (freq. =12) can provide insights on how households use their appliances, which can be used to improve product design (Bressanelli et al., 2018). Big data analytics facilitates the prediction of component lifetime and preventive maintenance (J. Li et al., 2015). It can be used for remote position reporting and route optimization to improve fleet and distribution management, and to enhance productivity by optimizing fuel efficiency (Kaleel Ahmed et al., 2018).

Blockchain technology (freq. =9) allows for smart contracts throughout all stages of the life cycle. These may be especially useful for tracking and control (Saberi et al., 2019). Data concerning the source of materials and products, the actors involved, the processes, and the energy consumption provide exemplary forms of information that can be made available on blockchain ledgers (Kouhizadeh et al., 2020).

IoT applications were found to be most frequent for the MOL stage. In contrast, for the BOL-MOL stages, blockchain applications were the most frequent (Figure 6b).

Blockchain technology (freq. $=7$ ) is utilized in maritime container management in the BOL and MOL stages to have more accurate and reliable bills of lading. This is currently done by Maersk, together with IBM (Saberi et al., 2019). Bumble Bee Foods uses this DT for consumers and retailers, who can now access the complete journey and processing history of yellowfin tuna. BMW also uses such technology for tracking cobalt supplies for electrical vehicle batteries (Kouhizadeh et al., 2020).

For the MOL phase, loT technology (freq. $=14$ ) is used to improve service design or product availability and to reduce operational costs. It is currently employed by ZipCar in vehicle management for such purposes. The company HP applies loT technology to monitor printer ink levels and ease the ordering and return of ink 
(a) Potentials

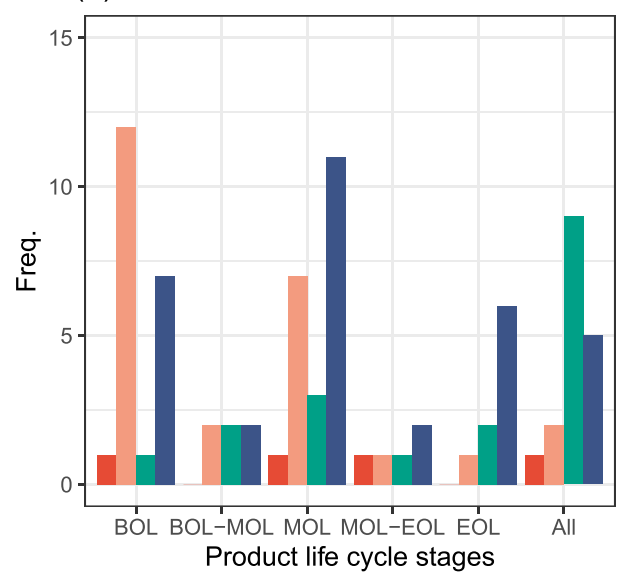

DT

Artificial Intelligence

Big Data (b) Applications

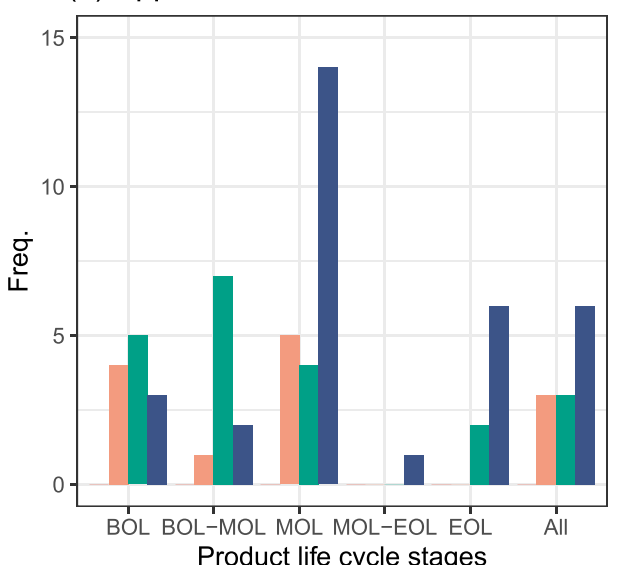

Product life cycle stages
FIGURE 6 Classification of

(a) potential $(n=80)$ and

(b) application $(n=66)$ examples of

digital technologies allocated to the product life cycle stages. Total $n=146$. Abbreviations: Freq., frequency; BOL, beginning-of-life; MOL, middle-of-life; EOL, end-of-life; DTs, digital technologies cartridges. The data from products-in-use also supports design for durability. Similarly, the "light-as-a-service" offering from Philips includes monitoring product faults in order to manage maintenance and repairs (Ingemarsdotter et al., 2019).

\subsection{Impact of digital technologies on sustainable product management areas}

In addition to the above procedure, an inductive coding approach was chosen to identify and cluster the most prevalent SPM areas and outcomes that may be improved or impacted by the use of DTs. As explained above, in Section 2.2, the SPM focus in this and the following section has been expanded so as to incorporate a more comprehensive sustainability perspective at the product level.

The inductive coding revealed that the DT examples examined could be used specifically in the following four areas of SPM: SCM, assessment, business modeling, and product design. When an example could not be assigned to one of these four specific areas, the category "SPM general" was used. This term includes the more universal applications of DTs, for example, blockchain applications that can efficiently validate information digitally, thus potentially supporting all the beforementioned SPM areas.

The inductive coding of the SPM outcomes resulted in the three categories: efficiency, transparency, and trustworthiness. In this study, the term efficiency is closely related to eco-efficiency which is defined as a "management strategy that combines environmental and economic performance" and it means, "doing more with less" (World Business Council for Sustainable Development [WBCSD], 2006, p. 16). For example, the improvement of operational efficiency (energy use) or the optimization of fuel efficiency in logistics are included in this category. The category transparency was used for DT examples that, for example, were used to share design knowledge, enabled traceability of products and components, or enabled different forms of condition and location monitoring. Under the term trustworthiness, we collated examples in which DTs overcome barriers to data sharing and exchange. These barriers mainly concern data confidentiality, actor reluctance or inability to share data, or a lack of secure and trustworthy data exchange routines. In these confidentiality and security related aspects the category trustworthiness also distinguished itself from the category transparency. Increased trustworthiness, for example, may be related to stakeholder use of bills of lading for ship containers, the secure data management of digital twins, or the sharing of car driving data or usage-based insurance.

The category of efficiency exhibited the highest frequency (freq. $=82$ ), followed by transparency (freq. $=27$ ) and trustworthiness (freq. = 11). In several cases, insufficient information was available for determining a specific SPM outcome as only the general potential of DTs was discussed. For these cases, the category "General potential" (freq. = 26) was used.

Figure 7 illustrates the outcomes per SPM area and DT for the full dataset of all 146 examples (see Figure B2 in the Supporting Information for the separate analysis of the 80 potential and 66 application examples). DTs are most frequently described as benefitting SPM in general (overall frequency $=62$ ). Examples for this category are an loT-based system that enables data-driven recycling decisions using lifecycle information (Kim et al., 2017), the use of loT sensors to measure the fill levels of scrap metal bins, and suggestions for optimal transport routes inside a factory (Mastos et al., 2020). Most of the examples in this category relate to loT technology, followed by blockchain technology and big data analytics. As illustrated already in Figure 6, especially loT and blockchain technology applications are dispersed throughout the product life cycle stages, and they have a potential for linking two, or even all, life cycle stages. This shows that their use is, in many cases, not limited to a specific area of SPM and can provide a more holistic view along the whole product life cycle. While the use of loT technology is solely linked with improved operational efficiency, blockchain technology provides, in most cases, increased trustworthiness. An example is a blockchain-enabled regulated recycling service (Liu et al., 2020). Another example is a 
blockchain-based groceries platform that benefits buyers and aims to reduce food waste (Teh et al., 2020).

The second most frequently mentioned area of SPM is (sustainable) SCM (freq. = 34), whereby the use of blockchain technology in increasing supply chain transparency is most frequently discussed. In addition, the use of loT and big data analytics can improve supply chain efficiency.

The assessment of products and services (freq. $=21$ ), mainly regarding environmental aspects, can be supported by loT technology in the collection of data along a product life cycle. And also blockchain technology is seen as an essential facilitator in this area, as it may increase the value chain actors' willingness to share potentially confidential environmental and social data which are needed for such assessments.

Regarding the business model (freq. $=15$ ), DTs are primarily attested to having a general potential for SPM. Their applications range from supporting value creation and capture in existing business models to enabling new types of value propositions in business models. Most examples of the latter follow a "virtualize" or "loop" strategy (see categories in Figure 5). The use of PSS, as one of several possible CE strategies, was also found in the literature, for example, Philips "light-as-a-service" offering is enabled by loT technology (Ingemarsdotter et al., 2019). Finally, some examples (freq. =14) discuss the general potential of big data analytics and loT technology in product design.

\section{5 | Use of digital technologies for sustainable product management activities}

Figure 8 adds an additional layer of detail to the analysis by illustrating which specific activities of SPM are (potentially) supported by the use of DTs. Out of all 146 examples, 123 provided enough detail for determining a specific SPM activity. As can be seen, Al may be used to collect and generate life cycle inventory data in an LCA, in supplier selection, in condition monitoring, and in the EOL phase, in order to

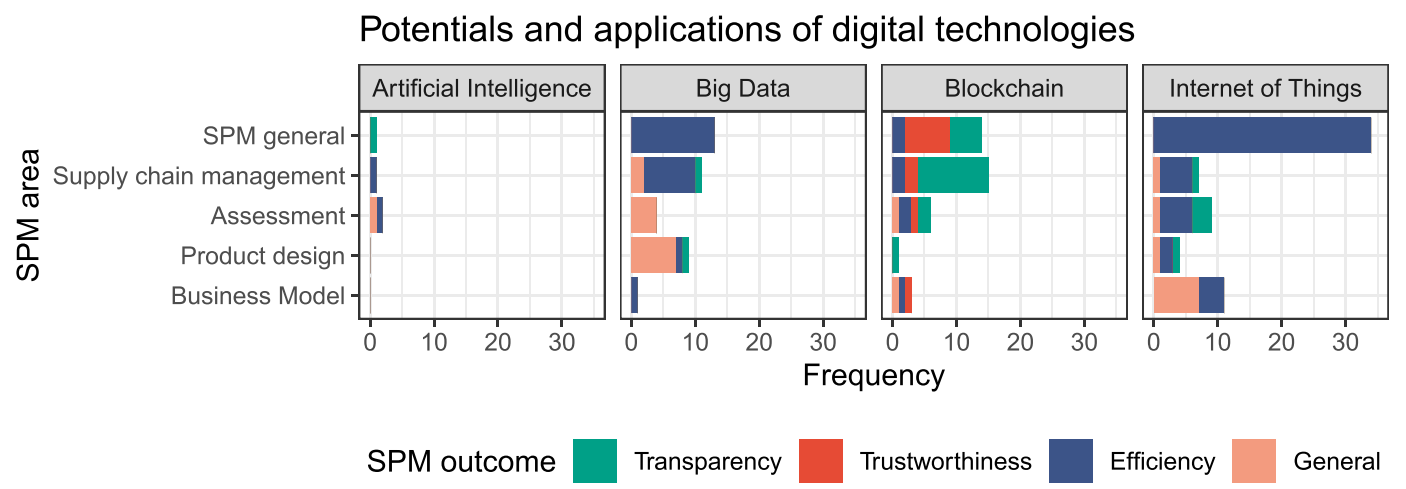

FIGURE 7 Classification of potential and application examples of digital technologies based on the area of application and the improved SPM outcome $(n=146)$. Abbreviation: SPM, sustainable product management

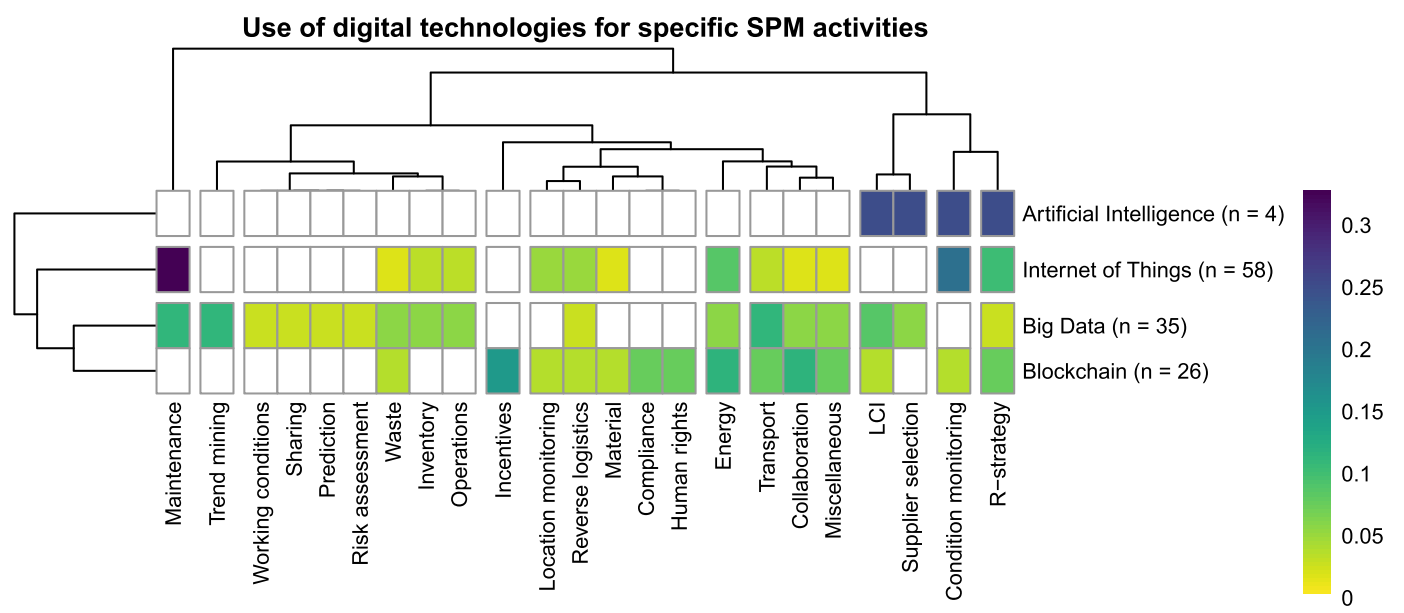

FIGURE 8 Overview of which specific activities of sustainable product management can be supported by which digital technologies. The shading indicates how many examples relate to a specific activity per technology. Distribution is normalized to 1 by digital technology (i.e., by row) $(n=123)$. Abbreviations: SPM, sustainable product management; $\mathrm{LCl}$, life cycle inventory 
support waste separation and, thus, enable different R-strategies. Additionally, an analysis was made of specific SPM activities per SPM area (Figure B3 in the Supporting Information)

IoT sensors have considerable potential for condition monitoring by capturing data on the real-time status of a product ( $Y$. Zhang, Ren, Liu, Sakao, \& Huisingh, 2017). These data can then be relayed to the supply chain stakeholders to identify any potential shipment delays (Manavalan \& Jayakrishna, 2019). To enable different R-strategies, for example, where desired, Cisco can track the location and condition of its sports shoes in order to identify customer replacement and upgrade needs. At the end of the life cycle, in a take-back model, consumers can return the shoes for remanufacturing to a location close to their home or work (Nobre \& Tavares, 2017).

Additionally, loT sensors are already frequently used in maintenance and manufacturing operations, even in a proactive sense. For example, data on aggregated real-time customer applications may be used as input to allow for adaptive product calibration so as to better match product operating conditions (Ge \& Jackson, 2014). A further example comes from the company "Whirlpool" which notifies customers concerning upcoming maintenance needs of their washing machines (Ingemarsdotter et al., 2019).

Furthermore, it can be seen that loT sensors, big data analytics, and blockchain technology all support the monitoring of energy and waste flows (Bressanelli et al., 2018; Chauhan et al., 2021), inventories (Kaleel Ahmed et al., 2018; J. Li et al., 2015), and operations in general (Corbett, 2018). In one case, the DTs are used for monitoring working conditions (Corbett, 2018) and two cases were found relating to compliance with human rights (Saberi et al., 2019; Teh et al., 2020). Furthermore, loT technology is used to monitor product locations and track transport routes, in general, and for reverse logistics, in particular. More rarely, it was used for tracking materials (Kouhizadeh et al., 2020; Tao et al., 2018) and for facilitating collaboration in manufacturing (Fahmideh \& Beydoun, 2019) or the building sector (Nobre \& Tavares, 2017). One application for facilitating collaboration was found at Nike. Here, a database was made accessible to designers willing to use sustainable materials in their products (Narayan \& Tidström, 2020).

As mentioned above, big data analytics is frequently used in maintenance activities and in monitoring energy and waste flows. Such activities include the prediction of the remaining lifetime of parts or components (J. Li et al., 2015), trend mining (Fahmideh \& Beydoun, 2019; Xu et al., 2015; Y. Zhang, Ren, Liu, Sakao, \& Huisingh, 2017), risk assessment (Kaleel Ahmed et al., 2018), and reusing distributed design knowledge and information for product family design and platform-based product development (J. Li et al., 2015).

The analysis of specific SPM activities reflects the supporting role that blockchain technology can have in activities revolving around information exchange. It can be used in the exchange of life cycle inventory data throughout the supply chain (Narayan \& Tidström, 2020; Saberi et al., 2019), as well as in condition monitoring (Liu et al., 2020), or in carbon emission trading based on smart contracts (A. Zhang et al., 2020). Blockchain technology can assist in ensuring the credibility of interorganizational production activities, for example, by allowing for greater security in the exchange of knowledge (about the sustainability performance) and services between enterprises (Z. Li et al., 2018) without the full provision of sensitive information leading to undue loss of competitive advantage or transparency (Kouhizadeh et al., 2020). Owing to its greater security, transparency, and accuracy, blockchain technology has significant potential in enabling smart-contracted verifications of sustainability-related data, thus allowing the development of new and sustainable business models and other business and industrial applications (Chapron, 2017; S. Li et al., 2020).

\section{5 | DISCUSSION}

This paper has investigated the various potential and application examples of DTs for SPM described in the literature.

First, the analysis of the literature shows that the number of studies about blockchain in conjunction with SPM (Figure 3) increased significantly from 7, in March 2019, to 53, in July 2020. A significant increase in studies was also observed for the terms CE and SSCM in conjunction with DT (Figure 4). It is very likely that this strong growth of research at the intersection of these fields will continue, particularly since ever more advanced DTs will become available for SPM in the next few years.

Second, the assessment and allocation of DT examples in terms of the ReSOLVE framework showed that the "optimize" strategy, which relates to increasing product performance and efficiency and removing waste from production and supply chains, is by far the most frequently discussed issue (Figure 5). So far, DTs have often merely been used for incremental improvements. Other ReSOLVE strategies, entailing more radical changes, for example, to business models or processes, are found much less frequently. One example found for the strategy "share" is that organizations use DTs to facilitate the delivery of products to the same region by sharing transportation means. Thus, using DTs to foster closer collaboration between different organizations (also outside their current partner networks) is an enabler for the transition towards a CE. More such examples are needed to encourage stepwise implementation of efficient, transparent, and reliable SPM processes, and thereby accelerate this transition.

Third, most of the studies in the sample focus either on one or two specific DTs or life cycle phases (e.g., loT in manufacturing) (Figure 6). Y. Zhang, Ren, Liu, and Si (2017) stated in their review that "[...] the overall solution for the whole life-cycle is seldom investigated" (p. 628). Additionally, they reported that solutions for the automatic identification and acquisition of product life cycle data (PLCD) are deficient. Both points can be confirmed by the present study. However, also the management of PLCD is essential to determine the sustainability implications of products. For instance, Kouhizadeh et al. (2020) reported that Walmart customers have begun to shift their attention from food nutrition information to food supply chain information. Thus, increasing customer awareness is pushing 
organizations towards pursuing SPM practices and towards rethinking current business strategies.

Fourth, the present study finds that SSCM, business models, assessment, and product design are the SPM areas that are most often affected by the use of DTs. The ensuing improvements in these areas were found to cluster around the three issues of efficiency, transparency, and trustworthiness between stakeholders (Figure 7). However, in order to use DTs in such a way that they benefit these SPM areas, the "human-side" (e.g., personal and intraorganizational issues) must also be considered. One example stated by Zhou et al. (2017) was that the increased use of DTs in companies required the formation of new departments to collect and process the PLCD in order to aid decision making in other departments. The level of application and implementation of DTs for SPM is also likely to be influenced by different factors such as technological affinity and/or company size. The assessment of the applications showed that it is mostly the large corporations which use DTs for their sustainability practices. While examining the reasons for this was not part of the present study, it remains an interesting topic for further research.

Fifth, the heatmap with the SPM activities per DT reveals the variety of topics covered by the 146 examples found in the present study (Figure 8). This result expands upon previous studies such as that by Nobre and Tavares (2017) which focused on big data and IoT applications in a CE. Their conclusion that these two DTs may be applied in many different areas of sustainability (e.g., closed-loop product lifecycle management, the establishment of sustainable cities, energy grid optimization, ecologically designed products and buildings, and sustainable agriculture) is confirmed in the present study.

While DTs are already widely used for environmental issues, only three studies (Corbett, 2018; Saberi et al., 2019; Teh et al., 2020) were found where DTs were used to benefit social sustainability issues. Kouhizadeh et al. (2020) state that the use of DTs for implementing CE targets has even led to a deterioration in social sustainability.

The creation of novel categorizations for the examples analyzed here (see Sections 4.2-4.5) has enabled us to provide a comprehensive overview of DT applications with respect to SPM. In the future, our coding scheme could be used to categorize new DT examples that are used for different SPM activities.

\section{6 | CONCLUSIONS}

We now draw relevant conclusions, address the limitations of the present study, and outline possible areas of future research.

First, DTs should not be considered separately from each other. It was found that, in many cases, DTs are not applied as stand-alone but as complementary tools. For example, loT technologies are used to collect various data, big data analytics, and $\mathrm{Al}$ are used to realize data management or processing and can also be applied to data mining. Thus, DTs are most fruitfully employed as complementary tools for SPM.
Second, the application of DTs in general management or operations occurred frequently, for example, using DTs to create new competitive advantage, grow revenue, or measure the financial impact of decisions before they are made. In most cases, the description of the utilization of the respective DT for SPM was relatively short, and it was not always clear which SPM outcome and area could be improved. A clear allocation and distinction of the DT examples proved challenging, and, thus, two independent coders were used to counteract potential biases in the inductive coding steps. While the resulting categorizations of the DT examples contribute to a clearer understanding of how they may facilitate SPM, continual research is needed to assess in which sustainability practice DTs can best be utilized.

Third, social sustainability topics were underrepresented, with only three examples represented in our analysis. Therefore, further studies with an explicit focus on the intersection of DTs or Industry 4.0 and social sustainability issues are needed.

Fourth, a more holistic view of the whole product life cycle and further interdisciplinary perspectives on using DTs for SPM can reveal new application and implementation approaches. For example, the current technology-driven approaches could be enhanced by empirical research to further assess the potential of DTs for SPM along the whole life cycle of a product. Such an empirical research approach could also help deepening the insights regarding the different DTs state of implementation in practice.

Additionally, apart from being a key aspect of SPM, the use of DTs throughout the whole product life cycle has clear managerial implications too. Decisions in the BOL stage can be the enabler for a product's circularity in a later life cycle phase (e.g., by deciding to include product sensors in the design phase) and directly impact the potential availability of product data in all the subsequent life cycle stages. Proactive DT approaches are also needed for collecting and managing product data in the MOL and EOL phases. Data management, data sharing, and interorganizational and intraorganizational collaboration-supported by DTs-from BOL to EOL stages are essential for SPM. The product data that are collected and shared after the BOL phase are particularly important for facilitating the circularity of resources. However, the value of such data depends on its usage, purpose, and context. To close the information gap in stages after the $\mathrm{BOL}$, one needs to collect data on the (current) status of the product or material and its availability. This is made possible by employing real-time monitoring concerning the product condition or location. Smart information collection and exchange ease the circularity of resources and help generate new competitive advantage. In addition, the increased likelihood of future resource scarcity or more stringent regulations makes this even more true.

This study contributes to a clearer understanding of the use of DTs in SPM. Nevertheless, the authors are also aware that this study shows certain limitations, for example, in the scope of research (with the selection of certain keywords and the exclusion of others) and the focus on the scientific literature. Working on more comprehensive and holistic data-driven SPM approaches provides a unique opportunity to contribute to a more sustainable CE. However, we argue that 
the scientific literature represents more advanced/proven concepts of how DTs can be used for SPM practices than, for example, the gray literature.

In summary, DTs can provide new possibilities for a more dynamic SPM but are currently insufficiently integrated in such activities. The results showed that the application of DTs can influence and improve a variety of sustainability areas. Moreover, the move from a linear economy to a CE is one challenge that DTs can help us meet. Various DT applications have addressed issues such as optimization, improving efficiency, and reducing costs. Up to now, DTs' full potential for extensive use in SPM has remained somewhat inchoate and blurry, and the potential use of product-related information throughout the full product life cycle tends to be neglected in practice. Thus, in order to unlock potential synergies of using DTs for SPM, a clear move needs to be made to raise understanding of the issues involved and to stimulate faster "translation" from theory to practice. So far, the use of DTs has mostly been concerned with incremental improvements. We argue, however, that a more holistic utilization of DTs could facilitate more radical changes and thereby have the potential to enable the circular disruptions needed in the current business environment.

\section{ACKNOWLEDGMENTS}

The financial support provided by the Austrian Federal Ministry for Digital and Economic Affairs, the National Foundation for Research, Technology and Development, and the Christian Doppler Research Association is gratefully acknowledged. The authors also want to thank Mr. David Mayer for his contribution to the prestudy. The authors acknowledge the financial support by the University of Graz.

\section{ORCID}

Magdalena Rusch (D) https://orcid.org/0000-0003-1681-0000 Josef-Peter Schöggl (D) https://orcid.org/0000-0002-4273-9490 Rupert J. Baumgartner (D) https://orcid.org/0000-0003-0956-7997

\section{REFERENCES}

Atzori, L., lera, A., \& Morabito, G. (2010). The Internet of Things: A survey. Computer Networks, 54(15), 2787-2805. https://doi.org/10.1016/j. comnet.2010.05.010

Awan, U., Sroufe, R., \& Shahbaz, M. (2021). Industry 4.0 and the circular economy: A literature review and recommendations for future research. Business Strategy and the Environment, 30(4), 2038-2060. https://doi.org/10.1002/bse.2731

Belaud, J. P., Prioux, N., Vialle, C., \& Sablayrolles, C. (2019). Big data for agri-food 4.0: Application to sustainability management for byproducts supply chain. Computers in Industry, 111, 41-50. https://doi. org/10.1016/j.compind.2019.06.006

Beltrami, M., Orzes, G., Sarkis, J., \& Sartor, M. (2021). Industry 4.0 and sustainability: Towards conceptualization and theory. Journal of Cleaner Production, 312, 127733. https://doi.org/10.1016/j.jclepro.2021. 127733

Berg, H., Le Blévennec, K., Kristoffersen, E., Strée, B., Witomski, A., Stein, N., Bastein, T., Ramesohl, S., \& Vrancken, K. (2020). Digital circular economy: a cornerstone of a sustainable European industry transformation [White paper]. European Circular Economy Research Alliance.

Bressanelli, G., Adrodegari, F., Perona, M., \& Saccani, N. (2018). Exploring How Usage-Focused Business Models Enable Circular Economy through Digital Technologies. Sustainability, 10(3), 639. https://doi. org/10.3390/su10030639

Brezet, H., \& van Hemel, C. (1997). ECODESIGN: A Promising Approach to Sustainable Production and Consumption. UNEP-Industry and Environment.

Buchert, T., Ko, N., Graf, R., Vollmer, T., Alkhayat, M., Brandenburg, E., Stark, R., Klocke, F., Leistner, P., \& Schleifenbaum, J. H. (2019). Increasing resource efficiency with an engineering decision support system for comparison of product design variants. Journal of Cleaner Production, 210, 1051-1062. https://doi.org/10.1016/j.jclepro.2018. 11.104

Cagno, E., Neri, A., Negri, M., Bassani, C. A., \& Lampertico, T. (2021). The role of digital technologies in operationalizing the circular economy transition: A systematic literature review. Applied Sciences, 11(8), 3328. https://doi.org/10.3390/app11083328

Ceschin, F., \& Gaziulusoy, I. (2016). Evolution of design for sustainability: From product design to design for system innovations and transitions. Design Studies, 47, 118-163. https://doi.org/10.1016/j.destud.2016. 09.002

Chapron, G. (2017). The environment needs cryptogovernance. Nature, 545(7655), 403-405. https://doi.org/10.1038/545403a

Chauhan, C., Sharma, A., \& Singh, A. (2021). A SAP-LAP linkages framework for integrating Industry 4.0 and circular economy. Benchmarking, 28(5), 1638-1664. https://doi.org/10.1108/BIJ-10-2018-0310

Copeland, M (2016). What's the difference between artificial intelligence, machine learning, and deep learning. Retrieved March 15, 2021, from NVIDIA Blog website. https://blogs.nvidia.com/blog/2016/07/29/ whats-difference-artificial-intelligence-machine-learning-deeplearning-ai/

Corbett, C. J. (2018). How sustainable is big data? Production and Operations Management, 27(9), 1685-1695. https://doi.org/10.1111/poms. 12837

de Jesus, A., \& Mendonça, S. (2018). Lost in Transition? Drivers and Barriers in the Eco-innovation Road to the Circular Economy. Ecological Economics, 145, 75-89. https://doi.org/10.1016/j.ecolecon.2017. 08.001

Ellen MacArthur Foundation. (2015). Growth within: a circular economy vision for a competitive Europe. Ellen MacArthur Foundation, SUN, McKinsey Center for Business and Environment.

European Commission. (2020). A new Circular Economy Action Plan-For a cleaner and more competitive Europe, Pub. L. No. COM(2020) 98 final. European Commission.

Fahmideh, M., \& Beydoun, G. (2019). Big data analytics architecture design-An application in manufacturing systems. Computers and Industrial Engineering, 128, 948-963. https://doi.org/10.1016/j.cie. 2018.08.004

Fink, A. (2005). Conducting research literature reviews: From the internet to paper (2.). SAGE Publications, Inc. https://doi.org/10.1111/j.13652648.2006.04033.x

Främling, K., Holmström, J., Loukkola, J., Nyman, J., \& Kaustell, A. (2013). Sustainable PLM through intelligent products. Engineering Applications of Artificial Intelligence, 26(2), 789-799. https://doi.org/10.1016/j. engappai.2012.08.012

Garrido-Hidalgo, C., Olivares, T., Ramirez, F. J., \& Roda-Sanchez, L. (2019). An end-to-end Internet of Things solution for reverse supply chain management in Industry 4.0. Computers in Industry, 112, 103127. https://doi.org/10.1016/j.compind.2019.103127

Garrido-Hidalgo, C., Ramirez, F. J., Olivares, T., \& Roda-Sanchez, L. (2020). The adoption of Internet of Things in a Circular Supply Chain framework for the recovery of WEEE: The case of lithium-ion electric 
vehicle battery packs. Waste Management, 103, 32-44. https://doi. org/10.1016/j.wasman.2019.09.045

Ge, X., \& Jackson, J. (2014). The big data application strategy for cost reduction in automotive industry. SAE International Journal of Commercial Vehicles, 7(2), 588-598. https://doi.org/10.4271/2014-01-2410

Geissdoerfer, M., Savaget, P., Bocken, N. M. P., \& Hultink, E. J. (2017). The Circular Economy-A new sustainability paradigm? Journal of Cleaner Production, 143, 757-768. https://doi.org/10.1016/j.jclepro.2016. 12.048

Gubbi, J., Buyya, R., Marusic, S., \& Palaniswami, M. (2013). Internet of Things (IoT): A vision, architectural elements, and future directions. Future Generation Computer Systems, 29(7), 1645-1660. https://doi. org/10.1016/j.future.2013.01.010

Ingemarsdotter, E., Jamsin, E., \& Balkenende, R. (2020). Opportunities and challenges in loT-enabled circular business model implementation-A case study. Resources, Conservation and Recycling, 162, 105047. https://doi.org/10.1016/j.resconrec.2020.105047

Ingemarsdotter, E., Jamsin, E., Kortuem, G., \& Balkenende, R. (2019). Circular strategies enabled by the Internet of Things-A framework and analysis of current practice. Sustainability (Switzerland), 11(20), 5689. https://doi.org/10.3390/su11205689

ISO. (2006). ISO 14044:2006. ISO.

Jerbia, R., Kchaou Boujelben, M., Sehli, M. A., \& Jemai, Z. (2018). A stochastic closed-loop supply chain network design problem with multiple recovery options. Computers and Industrial Engineering, 118(1), 23-32. https://doi.org/10.1016/j.cie.2018.02.011

Kaleel Ahmed, A., Senthilkumar, C. B., \& Nallusamy, S. (2018). Study on environmental impact through analysis of big data for sustainable and green supply chain management. International Journal of Mechanical and Production Engineering Research and Development, 8(1), 12451254. https://doi.org/10.24247/ijmperdfeb2018145

Kim, Y. W., Chang, T. W., \& Park, J. (2017). Gen2 RFID-based system framework for resource circulation in closed-loop supply chains. Sustainability, 9(11), 1995. https://doi.org/10.3390/su9111995

Kirchherr, J., Piscicelli, L., Bour, R., Kostense-Smit, E., Muller, J., Huibrechtse-Truijens, A., \& Hekkert, M. (2018). Barriers to the circular economy: Evidence from the European Union (EU). Ecological Economics, 150, 264-272. https://doi.org/10.1016/j.ecolecon.2018.04.028

Kirchherr, J., Reike, D., \& Hekkert, M. (2017). Conceptualizing the circular economy: An analysis of 114 definitions. Resources, Conservation and Recycling, 127, 221-232. https://doi.org/10.1016/j.resconrec.2017. 09.005

Korhonen, J., Honkasalo, A., \& Seppälä, J. (2018). Circular economy: The concept and its limitations. Ecological Economics, 143, 37-46. https:// doi.org/10.1016/j.ecolecon.2017.06.041

Kouhizadeh, M., Zhu, Q., \& Sarkis, J. (2020). Blockchain and the circular economy: Potential tensions and critical reflections from practice. Production Planning and Control, 31(11-12), 950-966. https://doi.org/10. 1080/09537287.2019.1695925

Kristoffersen, E., Aremu, O. O., Blomsma, F., Mikalef, P., \& Li, J. (2019). Exploring the relationship between data science and circular economy: An enhanced CRISP-DM process model. In I. O. Pappas, P. Mikalef, Y. K. Dwivedi, L. Jaccheri, J. Krogstie, \& M. Mäntymäki (Eds.), Digital Transformation for a Sustainable Society in the 21st Century. I3E 2019 (Vol. 11701). Lecture Notes in Computer Science (including subseries Lecture Notes in Artificial Intelligence and Lecture Notes in Bioinformatics). Springer. https://doi.org/10.1007/978-3-030-29374-1_15

Kurilova-Palisaitiene, J., Lindkvist, L., \& Sundin, E. (2015). Towards facilitating circular product life-cycle information flow via remanufacturing. Procedia CIRP, 29, 780-785. https://doi.org/10.1016/j.procir.2015. 02.162

Landis, J. R., \& Koch, G. G. (1977). The measurement of observer agreement for categorical data. Biometrics, 33(1), 159-174. https://doi.org/ $10.2307 / 2529310$
Li, J., Tao, F., Cheng, Y., \& Zhao, L. (2015). Big data in product lifecycle management. International Journal of Advanced Manufacturing Technology, 81, 667-684. https://doi.org/10.1007/s00170-015-7151-x

Li, S., Zhang, H., Yan, W., \& Jiang, Z. (2020). A hybrid method of blockchain and case-based reasoning for remanufacturing process planning. Journal of Intelligent Manufacturing, 32, 1389-1399. https://doi.org/10. 1007/s10845-020-01618-6

Li, Z., Liu, L., Barenji, A. V., \& Wang, W. (2018). Cloud-based manufacturing blockchain: Secure knowledge sharing for injection mould redesign. 51st CIRP Conference on Manufacturing Systems Cloud-Based, 72, 961-966. https://doi.org/10.1016/j.procir.2018.03.004

Liu, X. L., Wang, W. M., Guo, H., Barenji, A. V., Li, Z., \& Huang, G. Q. (2020). Industrial blockchain based framework for product lifecycle management in Industry 4.0. Robotics and Computer-Integrated Manufacturing, 63, 101897. https://doi.org/10.1016/j.rcim.2019. 101897

Lombard, M. (2002). Content analysis in mass communication: Assessment and reporting of intercoder reliability. Human Communication Research, 28(4), 587-604. https://doi.org/10.1093/hcr/28.4.587

Lopes de Sousa Jabbour, A. B., Jabbour, C. J. C., Godinho Filho, M., \& Roubaud, D. (2018). Industry 4.0 and the circular economy: A proposed research agenda and original roadmap for sustainable operations. Annals of Operations Research, 270, 273-286. https://doi.org/ 10.1007/s10479-018-2772-8

Manavalan, E., \& Jayakrishna, K. (2019). A review of Internet of Things (IoT) embedded sustainable supply chain for Industry 4.0 requirements. Computers and Industrial Engineering, 127, 925-953. https:// doi.org/10.1016/j.cie.2018.11.030

Massaro, M., Secinaro, S., Dal Mas, F., Brescia, V., \& Calandra, D. (2021). Industry 4.0 and circular economy: An exploratory analysis of academic and practitioners' perspectives. Business Strategy and the Environment, 30, 1213-1231. https://doi.org/10.1002/bse.2680

Mastos, T. D., Nizamis, A., Vafeiadis, T., Alexopoulos, N., Ntinas, C., Gkortzis, D., Papadopoulos, A., loannidis, D., \& Tzovaras, D. (2020). Industry 4.0 sustainable supply chains: An application of an loT enabled scrap metal management solution. Journal of Cleaner Production, 269, 122377. https://doi.org/10.1016/j.jclepro.2020.122377

Mayer, A., Haas, W., Wiedenhofer, D., Krausmann, F., Nuss, P., \& Blengini, G. A. (2018). Measuring progress towards a circular economy: A monitoring framework for economy-wide material loop closing in the EU28. Journal of Industrial Ecology, 23(1), 62-76. https://doi.org/ 10.1111/jiec.12809

Mayring, P. (2014). Qualitative content analysis theoretical foundation, basic procedures and software solution. Beltz.

Moher, D., Liberati, A., Tetzlaff, J., \& Altman, D. G. (2009). Preferred Reporting Items for Systematic Reviews and Meta-Analyses: The PRISMA statement. PLoS Medicine, 6(7), e1000097. https://doi.org/10. 1371/journal.pmed.1000097

Murray, A., Skene, K., \& Haynes, K. (2017). The circular economy: An interdisciplinary exploration of the concept and application in a global context. Journal of Business Ethics, 140(3), 369-380. https://doi.org/10. 1007/s10551-015-2693-2

Narayan, R., \& Tidström, A. (2020). Tokenizing coopetition in a blockchain for a transition to circular economy. Journal of Cleaner Production, 263, 121437. https://doi.org/10.1016/j.jclepro.2020.121437

Nobre, G. C., \& Tavares, E. (2017). Scientific literature analysis on big data and internet of things applications on circular economy: A bibliometric study. Scientometrics, 111(1), 463-492. https://doi.org/10.1007/ s11192-017-2281-6

Okoli, C., \& Schabram, K. (2010). A Guide to Conducting a Systematic Literature Review of Information Systems Research. Available at SSRN: https://doi.org/10.2139/ssrn.1954824

Pagoropoulos, A., Pigosso, D. C. A., \& McAloone, T. C. (2017). The Emergent Role of Digital Technologies in the Circular Economy: A Review. 
Procedia CIRP, 64, 19-24. https://doi.org/10.1016/j.procir.2017. 02.047

R Core Team. (2019). A language and environment for statistical computing. Retrieved August 11, 2020, from R Foundation for Statistical Computing website. http://www.r-project.org

Ranta, V., Aarikka-Stenroos, L., \& Väisänen, J.-M. (2021). Digital technologies catalyzing business model innovation for circular economyMultiple case study. Resources, Conservation and Recycling, 164, 105155. https://doi.org/10.1016/j.resconrec.2020.105155

Reike, D., Vermeulen, W. J. V., \& Witjes, S. (2018). The circular economy: New or refurbished as CE 3.0?-Exploring controversies in the conceptualization of the circular economy through a focus on history and resource value retention options. Resources, Conservation and Recycling, 135, 246-264. https://doi.org/10.1016/j.resconrec.2017. 08.027

Rocca, R., Rosa, P., Sassanelli, C., Fumagalli, L., \& Terzi, S. (2020). Integrating Virtual Reality and Digital Twin in Circular Economy Practices: A Laboratory Application Case. Sustainability, 12(6), 2286. https://doi. org/10.3390/su12062286

Rosa, P., Sassanelli, C., Urbinati, A., Chiaroni, D., \& Terzi, S. (2020). Assessing relations between circular economy and Industry 4.0: A systematic literature review. International Journal of Production Research, 58(6), 1662-1687. https://doi.org/10.1080/00207543.2019. 1680896

Saberi, S., Kouhizadeh, M., Sarkis, J., \& Shen, L. (2019). Blockchain technology and its relationships to sustainable supply chain management International Journal of Production Research, 57(7), 2117-2135. https://doi.org/10.1080/00207543.2018.1533261

Schöggl, J.-P., Stumpf, L., \& Baumgartner, R. J. (2020). The narrative of sustainability and circular economy-A longitudinal analysis of two decades of research. Resources, Conservation \& Recycling, 163, 105073. https://doi.org/10.1016/j.resconrec.2020.105073

Seuring, S., \& Gold, S. (2012). Conducting content-analysis based literature reviews in supply chain management. Supply Chain Management: An International Journal, 17(5), 544-555. https://doi.org/10.1108/ 13598541211258609

Seuring, S., \& Müller, M. (2008). From a literature review to a conceptual framework for sustainable supply chain management. Journal of Cleaner Production, 16(15), 1699-1710. https://doi.org/10.1016/j. jclepro.2008.04.020

Sivarajah, U., Kamal, M. M., Irani, Z., \& Weerakkody, V. (2017). Critical analysis of big data challenges and analytical methods. Journal of Business Research, 70, 263-286. https://doi.org/10.1016/j.jbusres.2016. 08.001

Spangenberg, J. H., Fuad-Luke, A., \& Blincoe, K. (2010). Design for Sustainability (DfS): The interface of sustainable production and consumption. Journal of Cleaner Production, 18(15), 1485-1493. https://doi.org/10. 1016/j.jclepro.2010.06.002

Stumpf, L., Schöggl, J.-P., \& Baumgartner, R. J. (2021). Climbing up the circularity ladder?-A mixed-methods analysis of 131 circular economy business strategies. Journal of Cleaner Production, 316, 128158. https://doi.org/10.1016/j.jclepro.2021.128158

Tao, F., Cheng, J., Qi, Q., Zhang, M., Zhang, H., \& Sui, F. (2018). Digital twin-driven product design, manufacturing and service with big data. International Journal of Advanced Manufacturing Technology, 94(9-12), 3563-3576. https://doi.org/10.1007/s00170017-0233-1

Teh, D., Khan, T., Corbitt, B., \& Ong, C. E. (2020). Sustainability strategy and blockchain-enabled life cycle assessment: A focus on materials industry. Environment Systems and Decisions, 40, 605-622. https://doi. org/10.1007/s10669-020-09761-4

Terzi, S., Bouras, A., Dutta, D., Garetti, M., \& Kiritsis, D. (2010). Product lifecycle management-From its history to its new role. International Journal of Product Lifecycle Management, 4(4), 360-389. https://doi. org/10.1504/IJPLM.2010.036489
Tu, M., Chung, W. H., Chiu, C. K., Chung, W., \& Tzeng, Y. (2017). A novel loT-based dynamic carbon footprint approach to reducing uncertainties in carbon footprint assessment of a solar PV supply chain. In 4th International Conference on Industrial Engineering and Applications, ICIEA 2017 (pp. 249-254). IEEE. https://doi.org/10.1109/IEA.2017. 7939216

United Nations Environment Programme. (2020). In C. Benoît Norris, M. Traverso, S. Neugebauer, E. Ekener, T. Schaubroeck, S. Russo Garrido, M. Berger, S. Valdivia, A. Lehmann, M. Finkbeiner, \& G. Arcese (Eds.), Guidelines for Social Life Cycle Assessment of Products and Organizations 2020. United Nations Environment Programme (UNEP).

Vadoudi, K., Allais, R., Reyes, T., \& Troussier, N. (2014). Sustainable product lifecycle management and territoriality: New structure for PLM. In IFIP International Conference on Product Lifecycle Management (pp. 475-484). Springer. https://doi.org/10.1007/978-3-662-459379_47

Vinuesa, R., Azizpour, H., Leite, I., Balaam, M., Dignum, V., Domisch, S., Felländer, A., Langhans, S. D., Tegmark, M., \& Fuso Nerini, F. (2020). The role of artificial intelligence in achieving the sustainable development goals. Nature Communications, 11(1), 1-10. https://doi.org/10. 1038/s41467-019-14108-y

Weckenmann, A., Bodi, Ş., Popescu, S., Dragomir, M., Hurgoiu, D., \& Comes, R. (2019). Hit or Miss? Evaluating the Potential of a Research Niche: A Case Study in the Field of Virtual Quality Management. Sustainability, 11(5), 1-26. https://doi.org/10.3390/su11051450

World Business Council for Sustainable Development. (2006). Ecoefficiency learning module. In World Business Council for Sustainable Development (WBCSD). Five Winds International.

Xu, M., Cai, H., \& Liang, S. (2015). Big data and industrial ecology. Journal of Industrial Ecology, 19(2), 205-210. https://doi.org/10.1111/jiec. 12241

Yang, S., Raghavendra, M. R. A., Kaminski, J., \& Pepin, H. (2018). Opportunities for Industry 4.0 to support remanufacturing. Applied Sciences (Switzerland), 8(7), 1177. https://doi.org/10.3390/app8071177

Zhang, A., Zhong, R. Y., Farooque, M., Kang, K., \& Venkatesh, V. G. (2020). Blockchain-based life cycle assessment: An implementation framework and system architecture. Resources, Conservation and Recycling, 152, 104512. https://doi.org/10.1016/j.resconrec.2019.104512

Zhang, Y., Ren, S., Liu, Y., Sakao, T., \& Huisingh, D. (2017). A framework for big data driven product lifecycle management. Journal of Cleaner Production, 159, 229-240. https://doi.org/10.1016/j.jclepro.2017.04.172

Zhang, Y., Ren, S., Liu, Y., \& Si, S. (2017). A big data analytics architecture for cleaner manufacturing and maintenance processes of complex products. Journal of Cleaner Production, 142, 626-641. https://doi.org/ 10.1016/j.jclepro.2016.07.123

Zhou, Z., Liu, X., Pei, J., Pardalos, P. M., Liu, L., \& Fu, C. (2017). Real options approach to explore the effect of organizational change on loT development project. Optimization Letters, 11(5), 995-1011. https://doi. org/10.1007/s11590-016-1006-8

\section{SUPPORTING INFORMATION}

Additional supporting information may be found in the online version of the article at the publisher's website.

How to cite this article: Rusch, M., Schöggl, J.-P., \& Baumgartner, R. J. (2022). Application of digital technologies for sustainable product management in a circular economy: A review. Business Strategy and the Environment, 1-16. https:// doi.org/10.1002/bse.3099 


\section{APPENDIX A: DETAILED REVIEW PROCESS AND RESULTS}

This section of the appendix provides a more detailed description of the keyword-based literature review (Table A1) and more detailed search results from each of the keyword combinations (Tables A2 and A3).

TAB LE A1 Analytic categories of the literature review with results (own representation based on Seuring \& Gold, 2012, p. 552)

\begin{tabular}{|c|c|}
\hline Description & Results \\
\hline Aim of research & $\begin{array}{l}\text { Exploring the status quo in the scientific literature of conceptual (potential) and existing applications of DTs for } \\
\text { SPM }\end{array}$ \\
\hline $\begin{array}{l}\text { Search query each SPM term with } \\
\text { each DT term }\end{array}$ & For example, TITLE-ABS-KEY (“circular econom*” AND "internet of things") \\
\hline $\begin{array}{l}\text { Number of publications and time } \\
\text { period covered }\end{array}$ & $\begin{array}{l}\text { By combining each SPM term with each DT term, } 375 \text { articles were found on March 1-4, 2019, in the Scopus } \\
\text { database and } 619 \text { journal articles were found on July 29, 2020. With the combined search query, } 330 \text { journal } \\
\text { articles (result without duplicates) with publication years ranging from } 1989 \text { to } 2021 \text { were found in July } 2020 .\end{array}$ \\
\hline
\end{tabular}

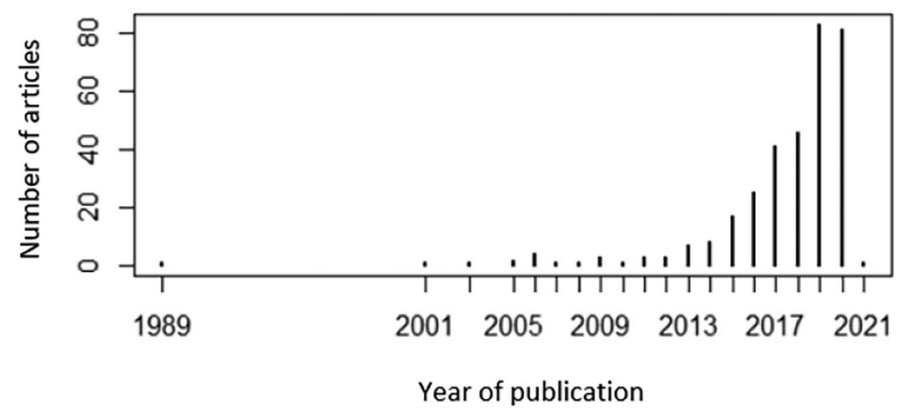

Method and type of data analysis Quantitative analysis in the "R" statistical tool and excel sheets and qualitative content analysis in MAXQDA (deductive and inductive coding approach)

Abbreviations: DT, digital technology; SPM, sustainable product management.

In Tables A2 and A3, the search results, first from March 1-4, 2019 (Table A2), and second from July 29, 2020 (Table A3), for the keyword combinations, are shown.

TAB LE A2 Search results from March 2019 in the Scopus database

\begin{tabular}{|c|c|c|c|c|c|c|c|c|c|c|}
\hline & $\begin{array}{l}\text { Circular } \\
\text { economy }\end{array}$ & PLM & $\begin{array}{l}\text { Life cycle } \\
\text { assessment }\end{array}$ & $\begin{array}{l}\text { Life cycle } \\
\text { analysis }\end{array}$ & $\begin{array}{l}\text { Eco } \\
\text { design }\end{array}$ & $\begin{array}{l}\text { Green } \\
\text { SCM }\end{array}$ & $\begin{array}{l}\text { Sustainable } \\
\text { SCM }\end{array}$ & $\begin{array}{l}\text { Industrial } \\
\text { ecology }\end{array}$ & $\begin{array}{l}\text { Life cycle } \\
\text { management }\end{array}$ & Sum \\
\hline loT & 15 & 25 & 8 & 8 & 0 & 1 & 7 & 2 & 33 & 99 \\
\hline $\begin{array}{c}\text { Industry } \\
4.0\end{array}$ & 15 & 11 & 3 & 0 & 1 & 3 & 7 & 0 & 12 & 52 \\
\hline Blockchain & 0 & 0 & 1 & 1 & 0 & 0 & 4 & 0 & 1 & 7 \\
\hline Sum & 45 & 57 & 61 & 37 & 6 & 17 & 55 & 11 & 86 & 375 \\
\hline
\end{tabular}

Abbreviations: Al, artificial intelligence; loT, internet of things; PLM, product lifecycle management; SCM, supply chain management. 
TAB LE A3 Search results from July 2020 in the Scopus database

\begin{tabular}{|c|c|c|c|c|c|c|c|c|c|c|}
\hline & $\begin{array}{l}\text { Circular } \\
\text { economy }\end{array}$ & PLM & $\begin{array}{l}\text { Life cycle } \\
\text { assessment }\end{array}$ & $\begin{array}{l}\text { Life cycle } \\
\text { analysis }\end{array}$ & $\begin{array}{l}\text { Eco } \\
\text { design }\end{array}$ & $\begin{array}{l}\text { Green } \\
\mathrm{SCM}\end{array}$ & $\begin{array}{l}\text { Sustainable } \\
\text { SCM }\end{array}$ & $\begin{array}{l}\text { Industrial } \\
\text { ecology }\end{array}$ & $\begin{array}{l}\text { Life cycle } \\
\text { management }\end{array}$ & Sum \\
\hline loT & 40 & 29 & 9 & 7 & 1 & 7 & 24 & 3 & 39 & 159 \\
\hline $\begin{array}{l}\text { Industry } \\
4.0\end{array}$ & 43 & 16 & 8 & 4 & 2 & 7 & 27 & 2 & 18 & 127 \\
\hline Sum & 123 & 74 & 69 & 49 & 7 & 39 & 132 & 12 & 114 & 619 \\
\hline
\end{tabular}

Abbreviations: Al, artificial intelligence; loT, internet of things; PLM, product lifecycle management; SCM, supply chain management. 